\title{
Impacts of Abnormal Heating of Tibetan Plateau on Rossby Wave Activity and Hazards Related to Snow and Ice in South China
}

\author{
Yuyue Fan, Guoping Li, and Huiguo Lu \\ College of Atmospheric Sciences, Chengdu University of Information Technology, Chengdu 610225, China
}

Correspondence should be addressed to Guoping Li; leegp@126.com

Received 1 December 2014; Accepted 24 February 2015

Academic Editor: Monique Leclerc

Copyright (C) 2015 Yuyue Fan et al. This is an open access article distributed under the Creative Commons Attribution License, which permits unrestricted use, distribution, and reproduction in any medium, provided the original work is properly cited.

\begin{abstract}
In January 2008, extreme freezing rain struck South China. At the same time, the Tibetan Plateau (TP) was experiencing pronounced surface heating. The characteristics of this extreme weather and its linkage to the TP surface heating anomaly were analyzed in this paper. The results show that (1) anomalous heating of the TP helps to form and sustain the Siberian blocking high, which is important for persistent southward flow of dry and cold Siberian air; (2) TP heating helps the moisture flux move more north and strengthens the southerly wind above $850 \mathrm{hPa}$; (3) there are two Rossby wave trains at $500 \mathrm{hPa}$ and the layers above it (at about $20^{\circ} \mathrm{N}-40^{\circ} \mathrm{N}$ ). Correlation analysis reveals that TP heating anomalies are closely associated with these Rossby wave trains; (4) the Rossby wave propagates downstream from the TP to South China in the mid and high layers of the atmosphere when the TP changes swiftly from a heat sink to a heat source. This implies that anomalous heating of the TP may stimulate the Rossby wave train to propagate downward in midlatitudes.
\end{abstract}

\section{Introduction}

The Tibetan Plateau (TP) is the highest terrain in the world, with an average elevation of more than $4000 \mathrm{~m}$. At such high altitude, the planetary boundary layer of the TP can extend to the middle atmosphere. Its topography and thermodynamic effects can influence the surrounding atmospheric circulation and weather [1], the propagation of Rossby waves, and sometimes even the transmission of stationary planetary waves [2-4].

The acceleration of downstream flow at midlatitude depends mainly on the interaction of Rossby waves and the westerly wind, which act as both a source and a response [5]. In subtropical climates, the dynamic and thermal effects of the terrain play a vital role in the interaction between a transient vortex and a stationary wave $[6,7]$.

Studies have shown that the TP has undergone significant warming in the past 50 years $[8,9]$, which means that atmospheric circulation may have impacted the region. Many previous studies have shown that the TP warming has had a significant impact on precipitation in China ([10-12]; etc.) as well as on the Asian monsoon ([13, 14], etc.). Under most circumstances, anomalous heating of the TP during summer contributes to more rainfall along the Yangtze River valley, whereas during winter, warmer conditions over the TP influence the East Asian winter monsoon [15]. Wang et al. [8] explored the impact of a TP surface temperature anomaly on the East Asian subtropical frontal rainfall and further proposed that the mechanism of linkage is two Rossby wave trains. However, most previous studies have concentrated on the possible mechanism of TP warming with regard to precipitation or monsoons in summer; few studies have focused on the impact of TP warming in winter.

The weather phenomena of snow and ice have some of the largest impacts on southern China and depend mainly on three factors: (1) stable weather conditions that are helpful for continuous southward intrusion of cold, such as long periods of blocking high; (2) warm and humid air originating from the sea mixing with cold and dry air originating from the north; and (3) stable stratified inversion layer.

In January 2008, an extremely hazardous period of snow and ice struck South China. It began on January 10 and lasted 
for more than 22 days, resulting in huge economic losses and serious social ramifications. A total of 21 provinces were affected, about 107 people are estimated to have died (4 people remain missing), more than $7,270,800$ ha of crops was destroyed, 223,000 houses were destroyed, and approximately 862,000 houses were damaged. Total economic losses are estimated at 111.1 billion yuan (RMB) (more detailed information can be seen on the following websites: http://www .chinadaily.com.cn/china/2008-02/18/content_6464154.htm, http://en.wikipedia.org/wiki/2008_Chinese_winter_storms).

Many scholars have analyzed the processes and possible contributory factors that brought about this prolonged period of heavy snowfall and low temperature (see, e.g., $[16,17]$ ). However, few studies have focused on synoptic waves and energy transformation with additional exploration of the possible connection with the TP heating anomaly. In this paper, we focus on the transfer of Rossby waves and their energy and analyze the role of anomalous TP heating in the 2008 ice/snow disaster in China.

\section{Data and Method}

2.1. Data. Surface heat flux data differ depending on the method of calculation, but different reanalysis data are in good agreement with regard to time series trends [18, 19]. The terrain of the TP is complicated, but some reports (see, e.g., $[19,20])$ have shown that the prevailing analysis of TP surface heat flux data (e.g., NCEP/NCAR, NCEP/DOE, and ERA40) is reliable, especially in winter and autumn. With regard to magnitude, the NCEP analysis data are closer to the measured data. Furthermore, compared with the data from NCEP/ NCAR, the NCEP/DOE has much better data on winter precipitation, surface and ground temperature, ground snow thickness, and shortwave radiation [21], and these improved data enable more accurate modeling of surface heat flux. Kanamitsu et al. [22] pointed out that the heat flux and temperature of the TP basically reflect the actual seasonal disturbances. Finally, using the same set of data ensures good dynamic consistency and coordination with other physical quantities; this is more advantageous for mechanism analysis because they use the same numerical prediction system.

This paper is based on NCEP/DOE data, which include daily latent heat flux and sensible heat flux data as well as data for wind (including zonal wind and meridional wind), temperature, and geopotential height.

2.2. Method. The surface heat-balance equation is as follows:

$$
R_{B}-F_{S}=F_{H}+F_{L}+F_{P}+F_{A} \text {, }
$$

where $R_{B}$ denotes radiation balance, $F_{S}$ is surface soil heat exchange flux, $F_{H}$ is ground (turbulent) sensible heat flux, $F_{L}$ is soil latent heat (evaporation), $F_{P}$ represents ground vegetation photosynthesis and various other heat conversion fluxes, and $F_{A}$ is the internal heat exchange of animal and plants metabolisms, and the heat exchange of the heat stored in plant tissues and the terrestrial vegetation canopy.
Since $F_{P}$ and $F_{A}$ are very small compared with the other components, they can generally be ignored, and the simplified heat-balance equation can be presented as follows:

$$
R_{B}-F_{S}=F_{H}+F_{L} .
$$

To study changes in ground surface heat $\left(F_{H}+F_{L}\right)$ in the TP, we choose an average of 190 lattice points within the region $\left(27-45^{\circ} \mathrm{N}, 70-105^{\circ} \mathrm{E}\right)$ to represent thermal intensity on the TP.

Takaya and Nakamura [23, 24] proposed a threedimensional wave activity flux to study the energy dispersion characteristics of the quasi-steady Rossby waves. Under the assumptions of the WKB approximation, flux is independent of the wave phase and moves in the same direction as the stationary Rossby wave train. Using spherical coordinates, the phase-independent wave action (W) can be expressed as

$$
\mathbf{W}=\frac{p \cos \varphi}{2|U|}\left\{\begin{array}{c}
\frac{U}{a^{2} \cos ^{2} \varphi}\left[\left(\frac{\partial \psi^{\prime}}{\partial \lambda}\right)^{2}-\psi^{\prime} \frac{\partial^{2} \psi^{\prime}}{\partial \lambda^{2}}\right] \\
+\frac{V}{a^{2} \cos \varphi}\left[\frac{\partial \psi^{\prime}}{\partial \lambda} \frac{\partial \psi^{\prime}}{\partial \varphi}-\psi^{\prime} \frac{\partial^{2} \psi^{\prime}}{\partial \lambda \partial \varphi}\right] \\
\frac{U}{a^{2} \cos \varphi}\left[\frac{\partial \psi^{\prime}}{\partial \lambda} \frac{\partial \psi^{\prime}}{\partial \varphi}-\psi^{\prime} \frac{\partial^{2} \psi^{\prime}}{\partial \lambda \partial \varphi}\right] \\
+\frac{V}{a^{2}}\left[\left(\frac{\partial \psi^{\prime}}{\partial \varphi}\right)^{2}-\psi^{\prime} \frac{\partial^{2} \psi^{\prime}}{\partial \varphi^{2}}\right] \\
\frac{f_{0}^{2}}{N^{2}}\left\{\frac{U}{a \cos \varphi}\left[\frac{\partial \psi^{\prime}}{\partial \lambda} \frac{\partial \psi^{\prime}}{\partial z}-\psi^{\prime} \frac{\partial^{2} \psi^{\prime}}{\partial \lambda \partial z}\right]\right. \\
\left.+\frac{V}{a}\left[\frac{\partial \psi^{\prime}}{\partial \varphi} \frac{\partial \psi^{\prime}}{\partial z}-\psi^{\prime} \frac{\partial^{2} \psi^{\prime}}{\partial \varphi \partial z}\right]\right\},
\end{array}\right.
$$

where $\psi^{\prime}$ denotes the quasi-geostrophic disturbance function, the quasi-geostrophic stream function can be defined as $\psi=\phi / f, \phi$ is a geopotential function, $f=2 \Omega \sin \varphi$, and $U=(u, v)$ represents the basic flow field.

Moisture flux vector $\left(\overrightarrow{W_{\mathrm{Q}}}\right)$ can be expressed as

$$
\overrightarrow{W_{\mathrm{Q}}}=\frac{1}{g} \cdot q \cdot \vec{V}
$$

where $q$ denotes specific humidity and $\vec{V}$ denotes wind vector.

\section{Time Evolution of TP Surface Heating in January 2008}

Figure 1 shows that the TP surface heat is much higher than the average climatic record (1979-2008), and there was also an increase in volatility (with a short cycle of 3 days and a longer cycle of 7-10 days). In particular, from January 7 to 11 , surface heat flux showed a significant increase of nearly $30 \mathrm{~W} / \mathrm{m}^{2}$ in 4 days. Around January 19 to 20, a second, more intense peak was reached. Subsequently, surface heating remained high with only small fluctuations.

The ice/snow disaster that struck South China in January 2008 can be divided into four stages [16]: January 10-15, 


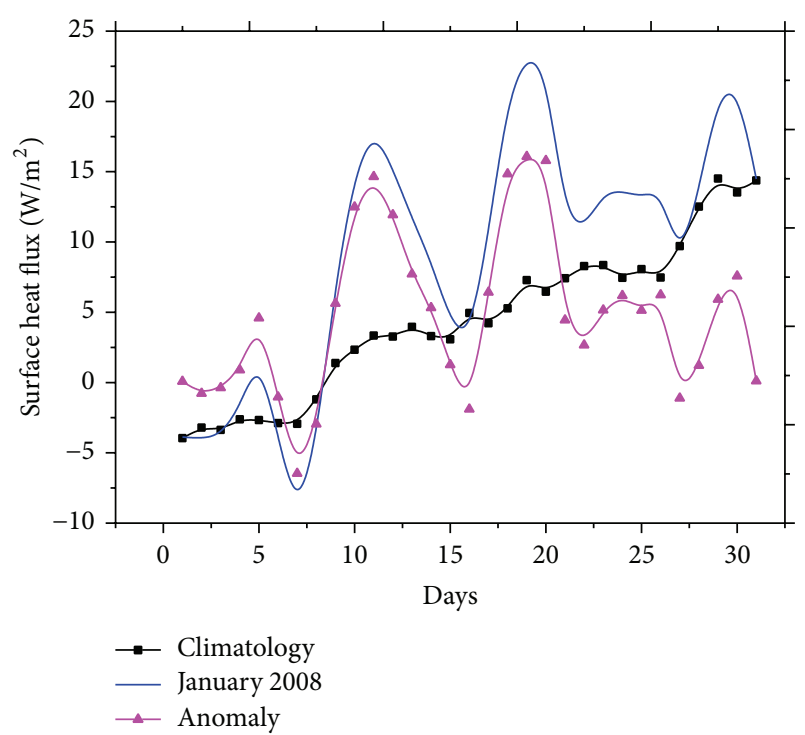

FIgURE 1: Time evolution of TP surface heat flux in January 2008.

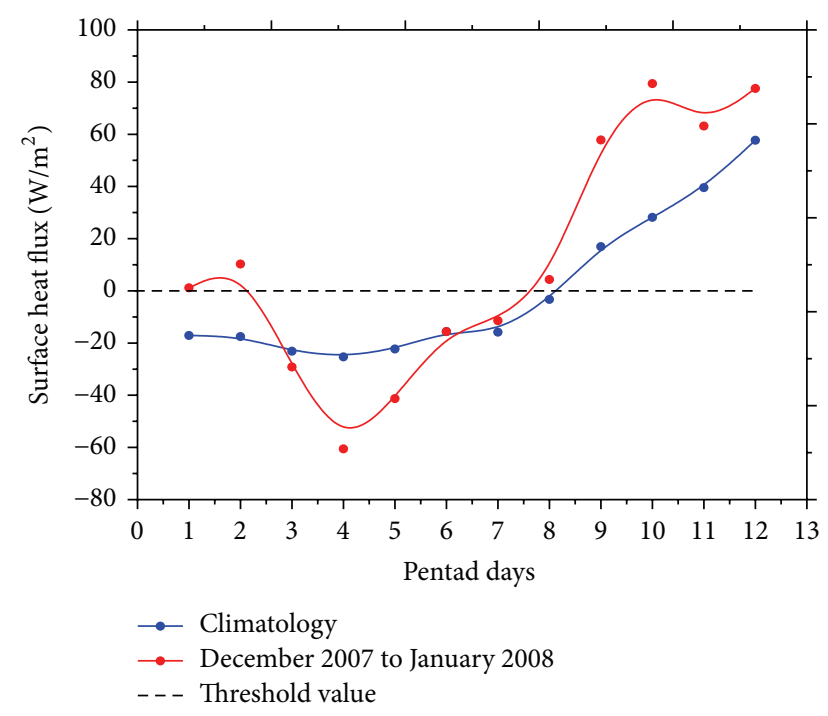

FIGURE 2: Time series of pentad accumulation of surface heat flux in TP (December 2, 2007-January 30, 2008).

January 18-22, January 25-28, and January 31-February 2. These four stages correspond to the unusual increase in the TP surface heating source.

To filter out the instability of the diurnal difference, we calculated each five-day (pentad) accumulation of surface heat flux from December 2, 2007, and compared it with climatic records (see Figure 2).

Figure 2 shows that surface heat flux on the TP remains lower than the typical level during the first eight pentads but is higher during the ninth and tenth pentads (the second ten-day period of January). In December 2007, thermal conditions on the TP underwent large fluctuations with continuous cooling in the first four pentads followed by subsequent warming. The increasing trend was maintained

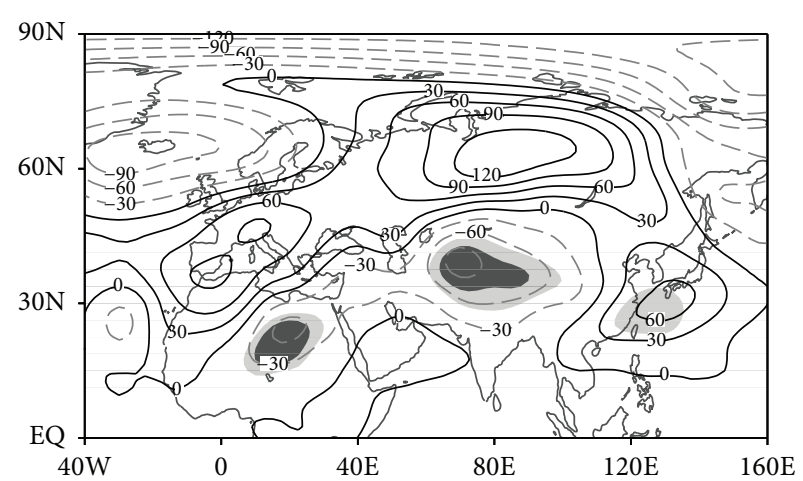

(a)

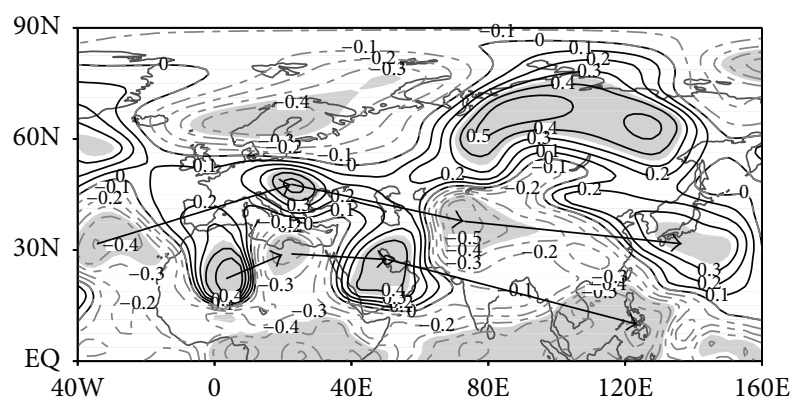

(b)

FIgURE 3: Composite $500 \mathrm{hPa}$ geopotential height field departure and $t$-test for January 11-30, 2008 (a), and correlation coefficient analysis of plateau surface heating anomaly and $500 \mathrm{hPa}$ geopotential height anomaly (b) (the shaded gray area is significant at $95 \%$ confidence level ( $t$-test); the solid/dotted line indicates positive/negative anomaly or connection).

from mid-December 2007 to the end of January. In particular, in pentads 9-11 (corresponding to January 11-25, 2008), surface heat on the TP was much higher than normal.

\section{Possible Impact of TP Heating on Icy Weather in South China in Early 2008}

The TP is conventionally considered as a heat sink in winter. However, when diabatic heating is extremely strong from top to bottom, the plateau is dominated by a consistent cyclonic circulation anomaly and a positive pressure anomaly [25]. This cyclone strengthens the southwesterly flow, which can affect the south branch flow as well as the West Pacific subtropical high. All of these factors may have played important roles in the occurrence and persistence of freezing weather in South China in 2008.

4.1. Analysis of $500 \mathrm{hPa}$ Geopotential Height Field. A comparison of Figures 3(a) and 3(b) shows that the spatial arrangement of correlation analysis (Figure 3(b)) is similar to the snow disaster peak time geopotential height anomaly (January 11-30, 2008, Figure 3(a)). At high latitude (about $60^{\circ} \mathrm{N}$ ), at around $60-120^{\circ} \mathrm{E}$, there is an unusually high geopotential height anomaly (Figure 3(a)), which corresponds with the positive connection center on the correlation analysis 


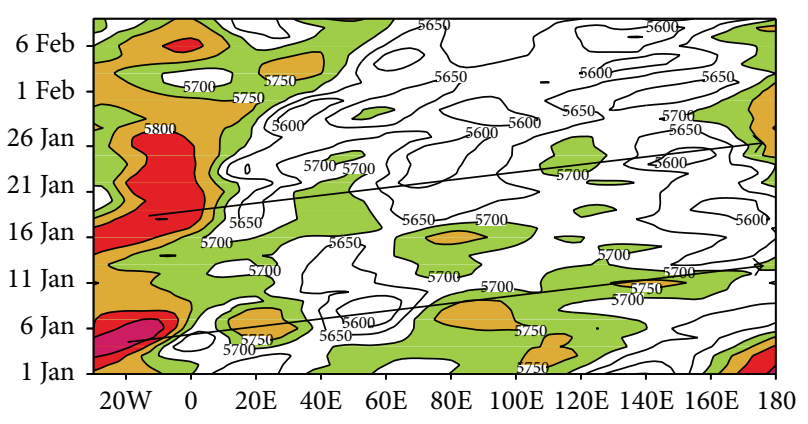

FIgURE 4: Profile of time and longitude with meridional-averaged geopotential height at $20-40^{\circ} \mathrm{N}$ from January 1 to February 10, 2008, at $500 \mathrm{hPa}$.

figure (Figure 3(b)). This indicates that anomalous heating of the TP helps to bring about high pressure in Siberia and facilitates the flow of cold, dry air to South China through the eastern edge of the TP. According to Wang and Ding [26], the stronger the Siberia high is the more cold will outburst in China. In the upstream area of Siberia, there is a negative correlation center that also corresponds with the abnormal low pressure center observed in the geopotential height anomaly (Figure 3(a)); thus the geopotential height over Europe will be low. This configuration is beneficial in developing and sustaining the Siberian blocking high in downstream areas.

Compared with climatic records, there was much lower geopotential height over the TP in January 2008, and the correlation analysis shows a negative correlation center there. Therefore, when surface heating of the TP increases, the warm air rises and the local pressure drops.

Contrary to the characteristics over the TP, the geopotential height anomaly at $\left(130^{\circ} \mathrm{E}, 30^{\circ} \mathrm{N}\right)$ is a positive center (Figure 3(a)), and the correlation analysis shows similar feature. However, the positive correlation center (Figure $3(\mathrm{~b})$ ) is further north than the anomaly (Figure 3(a)). In South China, such as the Bay of Bengal and the South China Sea, there is a negative correlation center that is statistically significant at the 95\% confidence level based on Student's $t$-test, which implies that anomalous heating over the TP promotes the development of a southern trough and provides plentiful water vapor to South China.

It is worth noting that there are two Rossby wave trains characterized by the alternatively positive and negative variations from west to east at latitudes $20-40^{\circ} \mathrm{N}$.

Moreover, from Figure 4, we can identify two Rossby waves (indicated by arrows) starting from January 6, 2008, which are at the same latitude as that in Figure 3. According to the theory of long-wave energy dispersion, the upstream Rossby wave train can influence energy for weather systems in downstream areas, which provides energy for those systems that generated the snow disaster; the details are analyzed in Section 5.

4.2. Stream Field Analysis. To further investigate the existence of the Rossby wave train identified in Figure 3(b), we analyzed the stream field at 300 and $500 \mathrm{hPa}$. Because both

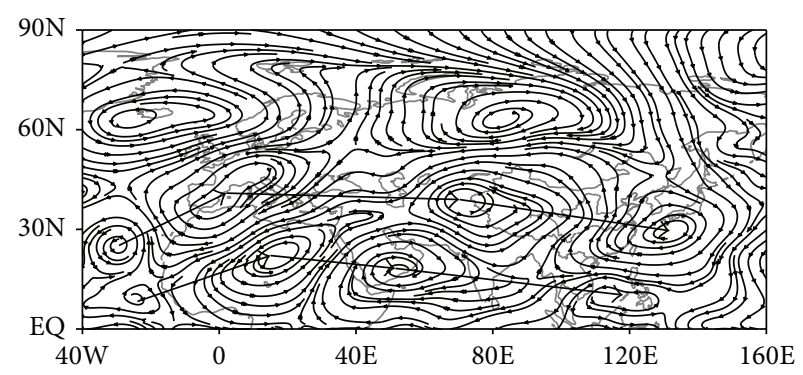

(a)

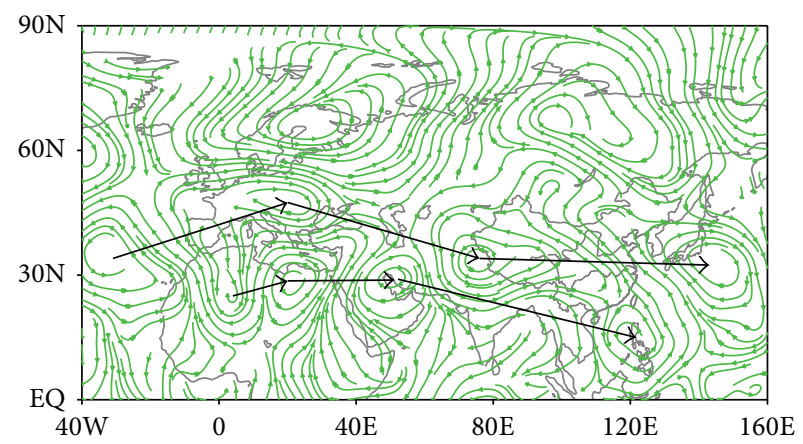

(b)

FIGURE 5: $500 \mathrm{hPa}$ stream field departure from January 11 to 30 , 2008 (a), and correlation analysis between plateau surface heating anomaly and $500 \mathrm{hPa}$ stream anomaly (b).

situations were found to be very similar, we only report on the $500 \mathrm{hPa}$ stream field here.

From Figure 5(a), it is seen that the east of China is dominated by an anticyclonic anomaly, which leads to ample mild, wet air flowing to South China. However, the plateau and its surrounding areas are dominated by a strong cyclonic anomaly, which supports the theory that abnormal TP surface heating causes the warm air near the surface to rise and converge with the surrounding air. At the same time, two series of cyclonic circulation and anticyclonic circulation appeared alternatively, from west to east (as shown by the arrows in Figure 5(a)), which is consistent with the findings at $500 \mathrm{hPa}$ geopotential height (Figure 3(b)).

To discuss the possible impact of the TP thermal anomaly on the stream field, the vector composition method is used to synthesize the stream figure shown in Figure 5(b). Comparison shows that Figures 5(b) and 5(a) are similar, especially in midlatitudes, but the vectorial resultant is shifted slightly towards the north and east.

The vectorial resultant shows that the main body of the TP is cyclonic while that of the West Pacific is anticyclonic. Under the coactions of these two circulations, ample humid air will flow to South China for the strong southerly wind. At the same time, the Rossby wave train shown previously (Figures 3(b) and 5(a)) can also be seen here (Figure 5(b)). Therefore, it may be concluded that the TP surface heating anomaly has a significant impact on the mid and high layers of the atmosphere, especially in midlatitudes. The Rossby wave train provides energy and water vapor for South China, which significantly influences the occurrence of freezing rain. 


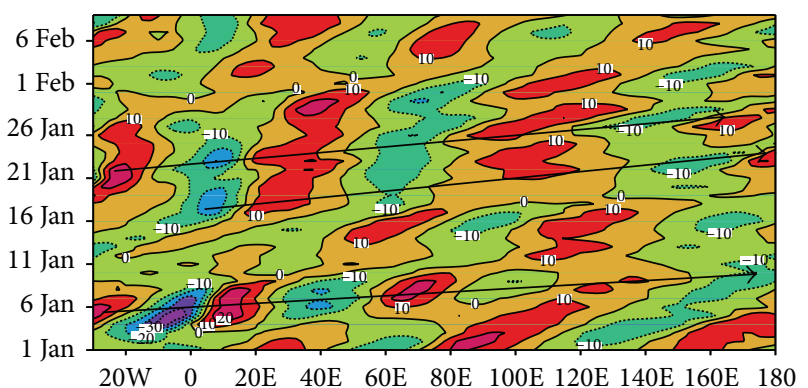

Figure 6: Time-longitude cross section of the $300 \mathrm{hPa}$ meridional wind, averaged over $20-40^{\circ} \mathrm{N}$, from January 1 to February 10, 2008.

\section{Influence of Rossby Wave Activity on Freezing Precipitation}

In Section 4 , the results suggested a series of Rossby wave-like trains at $20-40^{\circ} \mathrm{N}$, related to the TP thermal anomaly. Under the influence of the downstream effect of Rossby wave energy dispersion, the Rossby wave provides energy for freezing precipitation in South China. Tao et al. [27] pointed out that there were three Rossby wave trains in midlatitudes from January 1 to February 10, 2008. To further understand the features of downstream energy dispersion in January 2008, we examined the meridional wind, averaged over $20-40^{\circ} \mathrm{N}$, at $300 \mathrm{hPa}$ (Figure 6).

According to Section 3, thermal conditions over the TP were abnormally low in December 2007 but then they were unusually high in January 2008. To further study the possible impacts of TP thermal anomalies on Rossby wave energy propagation, we use Rossby wave activity to contrast the dispersion of Rossby wave energy.

Figure 7(a) shows a high geopotential height anomaly center in Eastern Europe, and the Rossby wave transmits from the east of this center to the low center around East Asia (about $60^{\circ} \mathrm{N}$ ). The wave energy is very weak at this low center, which means the wave encounters a barrier there and the energy is dissipated. However, toward the east of this center, the wave is stimulated again and propagates downstream. At midlatitudes, in the upstream areas of the plateau, wave activity propagates along the negative and positive alternate center of the geopotential height anomaly, but in the downstream areas of the plateau there is no more wave activity.

Figure 7(b) illustrates that Eastern Europe is occupied by a positive geopotential height anomaly. The Rossby wave transmits from the east of this center to the west of the Iranian Plateau, and the wave is dispersed over the Iranian Plateau. However, to the east, the wave flux strengthens again and propagates to the west of the TP. The wave is blocked by the terrain and the wave energy is dispersed; the wave activity strength is less than $5 \mathrm{~m} / \mathrm{s}^{2}$. However, wave activity increased east of the plateau and propagated to South China, providing energy for the freezing precipitation there.

Comparing Figure 7(b) with Figure 7(a) shows that the TP was a wave activity divergent center in January 2008 (Figure 7(b)), which means that the TP is a wave source. It is likely that several factors influenced the stimulation of

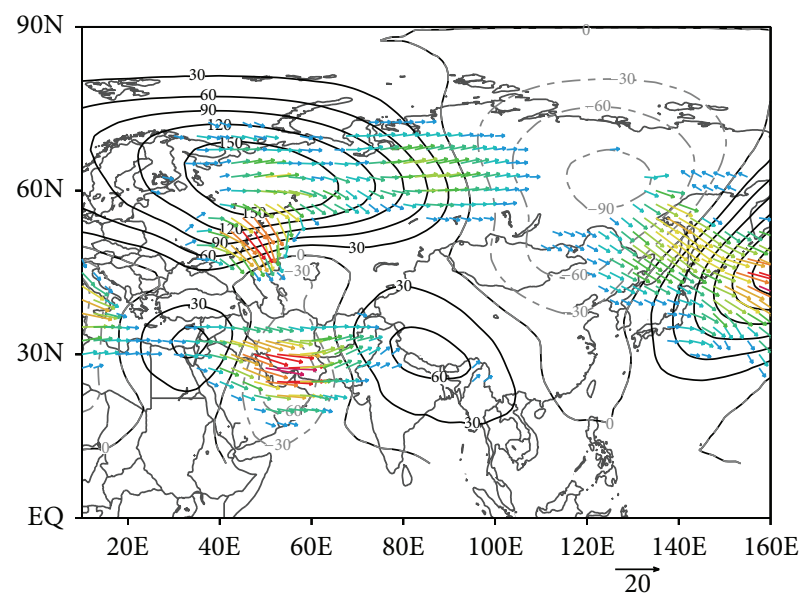

(a)

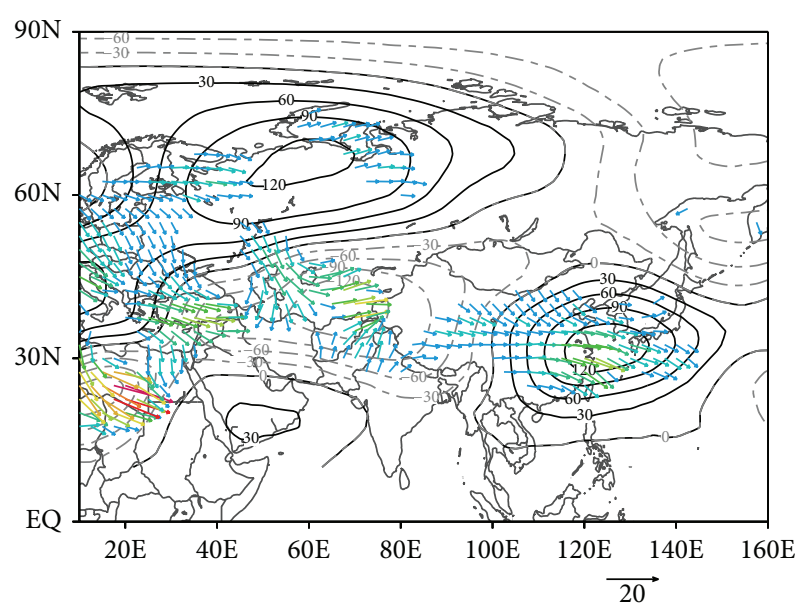

(b)

FIGURE 7: Composite of geopotential height anomaly (unit: gpm) and wave activity flux (unit: $\mathrm{m} / \mathrm{s}^{2}$ ) at $300 \mathrm{hPa}$ : monthly averages of December 2007 (a) and January 2008 (b) (wave activity flux less than $5 \mathrm{~m} / \mathrm{s}^{2}$ is omitted).

the wave there. However, in December 2007 (Figure 7(a)), the wave activity did not propagate further when it reached the TP. Therefore, it can be inferred that abnormal TP surface heating may affect the stimulation and propagation of the Rossby wave.

Many studies $[1,2]$ have proposed that the thermal and dynamic mechanism of the TP is a primary factor in the stimulation and propagation of Rossby waves. The characteristics of Rossby wave activity at $500 \mathrm{hPa}$ are similar but much weaker than those at $300 \mathrm{hPa}$.

\section{Impact of the TP Thermal Anomaly on the Low-Level Wind Field}

Figure 8 depicts the moisture flux anomaly during the snow/ ice disaster. At $700 \mathrm{hPa}$ (Figure 8(a)), the moisture flux is much higher than normal in South China. The moisture tunnel that flows to South China can be divided into three components: (1) the westerly moisture flux at about $25^{\circ} \mathrm{N}$. This kind of moisture flux is very small, especially at levels 


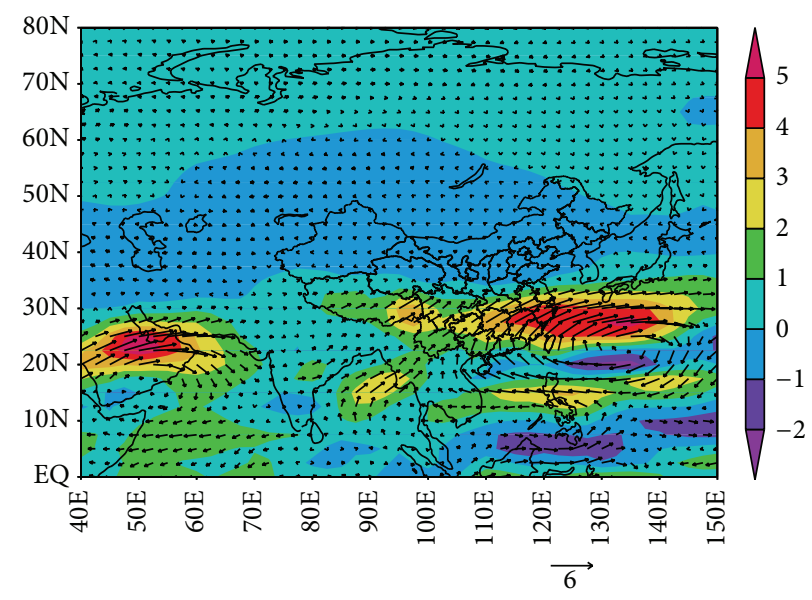

(a)

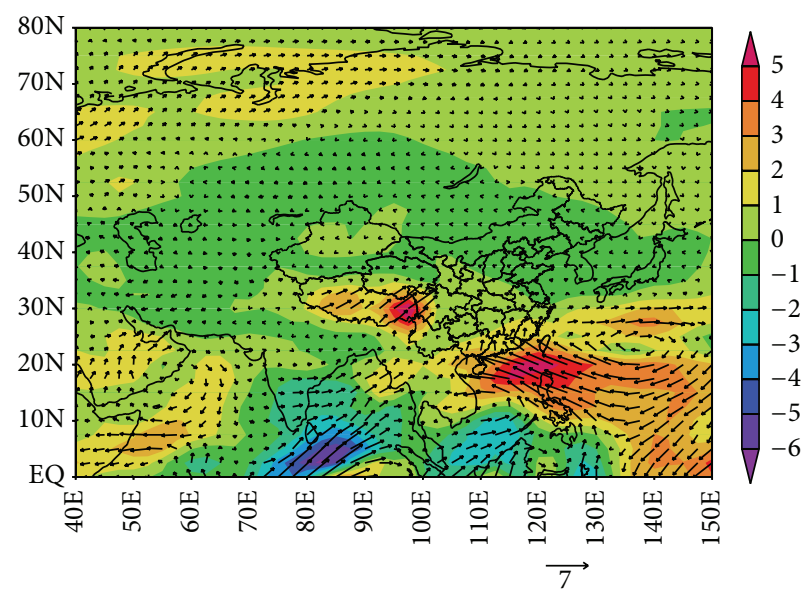

(b)

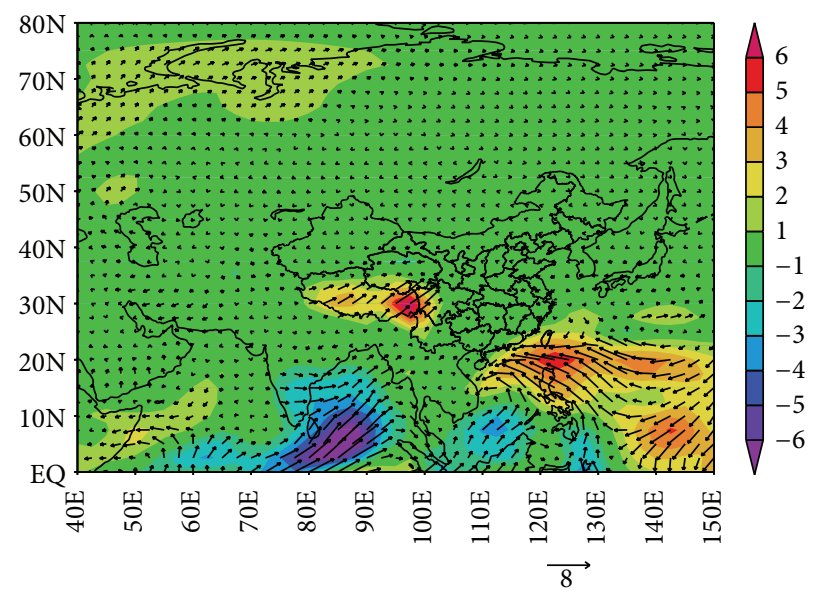

(c)

Figure 8: Moisture flux departure from January 11 to 30, 2008, at $700 \mathrm{hPa}(\mathrm{a}), 850 \mathrm{hPa}$ (b), and $925 \mathrm{hPa}$ (c) (the shaded area represents moisture flux anomaly, the wind vector made by latitude moisture flux anomaly, and zonal moisture flux anomaly; unit: $\left.\mathrm{g} \cdot \mathrm{cm}^{-1} \cdot \mathrm{s}^{-1}\right)$.

lower than $700 \mathrm{hPa}$, due to obstruction by the plateau; (2) the southwesterly moisture flux from the Bay of Bengal. This is a very important vapor source for the January 2008 disaster; (3) the southeasterly moisture flux from the South China Sea, the moisture flow along the southeast wind anomaly of the West Pacific subtropical high. This is the most important vapor supply for South China, especially at levels lower than $700 \mathrm{hPa}$.

At $850 \mathrm{hPa}$ (Figure 8(b)), due to obstruction by the terrain, the moisture flux anomaly in South China is very small, with only a slightly positive moisture flux anomaly on the southeast coast of China. Meanwhile, at $925 \mathrm{hPa}$ (Figure $8(\mathrm{c})$ ), the moisture flux anomaly mainly happens on the areas southern to $20^{\circ} \mathrm{N}$.

All in all, the moisture flux can transport to higher latitude at higher height level. So, it is more likely to see the positive moisture flux anomaly center in northern latitudes in China.

Comparison of the wind anomaly at different pressure levels shows that, South China is dominated by southerly wind anomaly at $850 \mathrm{hPa}$ (Figure 9 (a)) and $700 \mathrm{hPa}$, and dominated by northerly wind anomaly at $925 \mathrm{hPa}$
(Figure 9(b)). At $925 \mathrm{hPa}$ (Figure 9(b)), the northerly wind comes from the land, and is dry and cold, so the moisture flux is very low. However, at $850 \mathrm{hPa}$ (Figure 9(a)), the southerly wind originates from the South China Sea or the Bay of Bengal, which is wet and warm, so the moisture flux is greater than $925 \mathrm{hPa}$ (Figure 9(b)). As the plateau and other topographic features block the air flow, the $850 \mathrm{hPa}$ (Figure 9(a)) moisture flux anomaly is much less than $700 \mathrm{hPa}$.

To further discuss the influence of the TP thermal anomaly on wind field and moisture flux, correlation analyses were performed with the plateau surface heat source anomalies and 700-, 850-, and 925-hPa wind fields of $u, v$, respectively; subsequently, the vector composition method was used to synthesize the wind field (Figure 10).

The correlation between the TP heating anomaly and the moisture flux anomaly displays a large, significantly positive area in South China at and lower than $700 \mathrm{hPa}$ (Figures 10(a)10(c)). This demonstrates that TP heating is closely associated with moisture flux increase in South China. Of these, the positive correlation areas at $925 \mathrm{hPa}$ and $850 \mathrm{hPa}$ are bigger than $700 \mathrm{hPa}$, in which the significant area is centralized over a more northern area. 


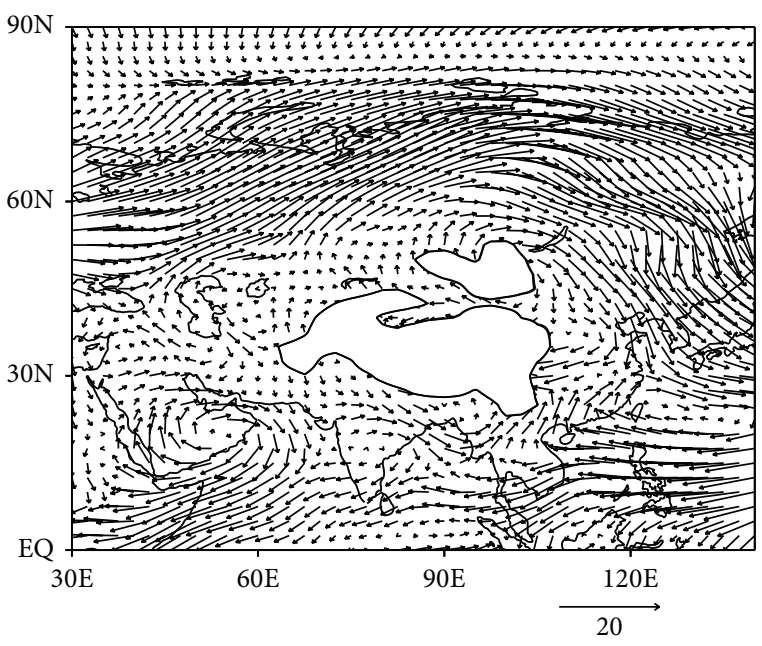

(a)

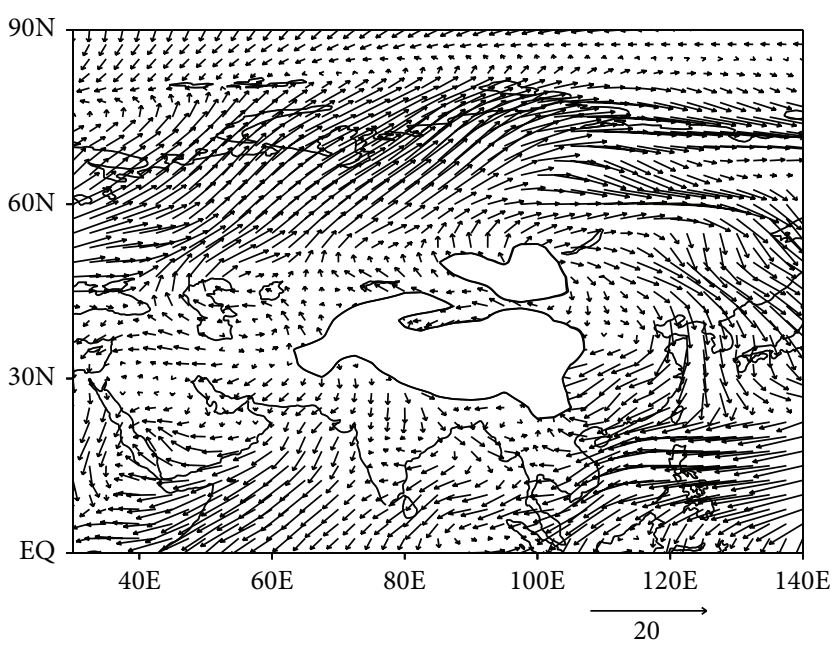

(b)

Figure 9: Wind field departure from January 11 to 30, 2008, at $850 \mathrm{hPa}$ (a) and $925 \mathrm{hPa}$ (b) (unit: $\mathrm{m} / \mathrm{s}$ ).

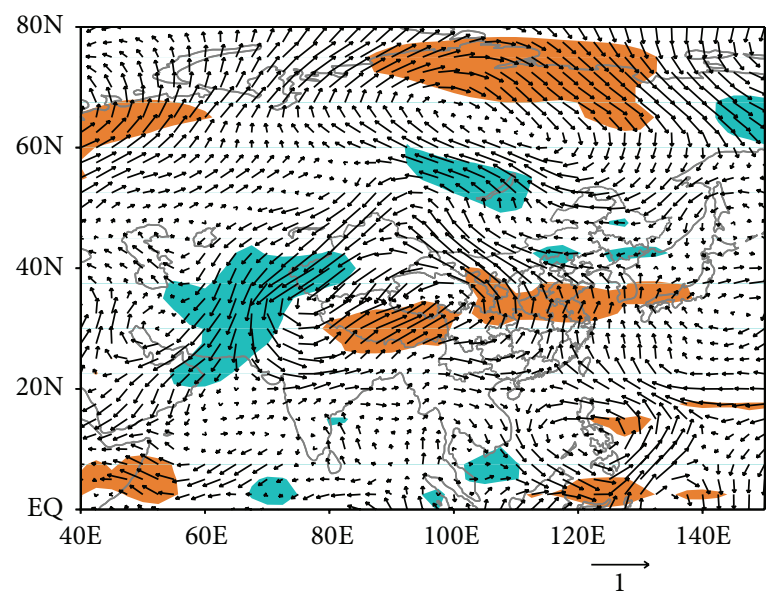

(a)

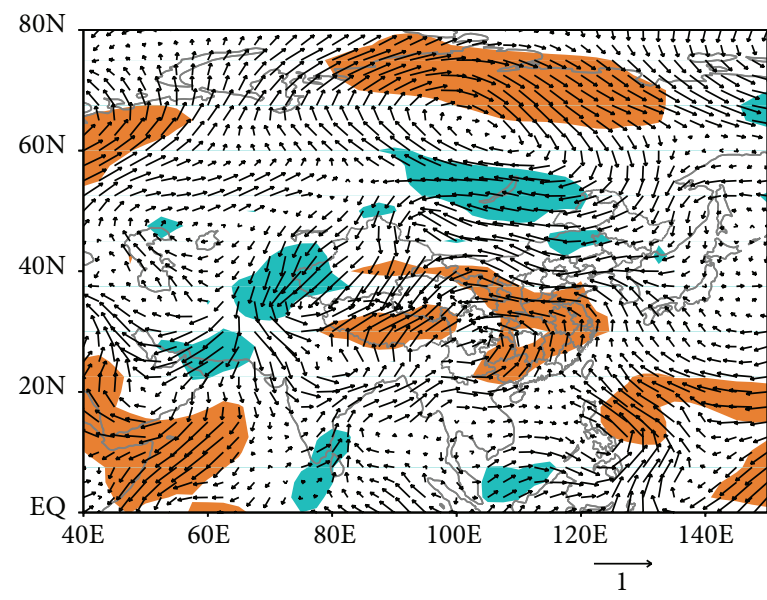

(b)

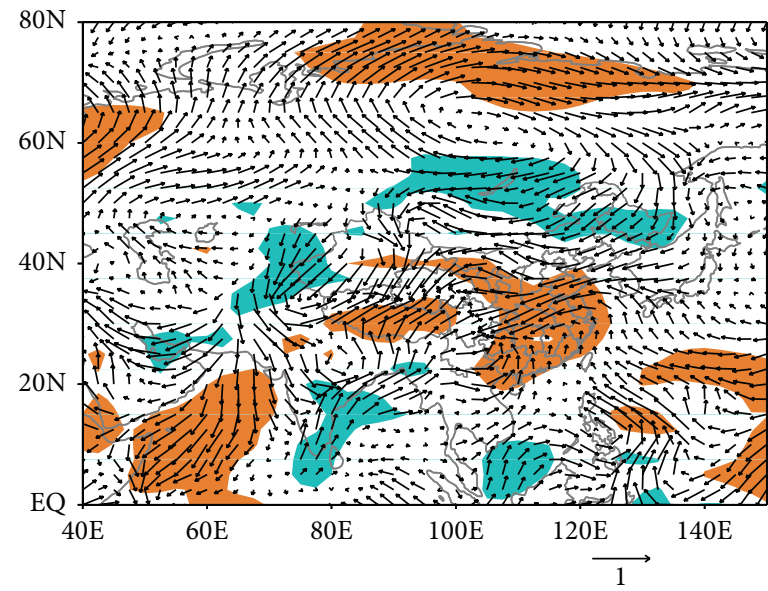

(c)

FIGURE 10: Correlations between the plateau surface heating anomaly and moisture flux anomaly and composited wind derived via correlation analysis between the plateau surface heating anomaly and the $u, v$ wind anomaly in January 2008 (the shaded area denotes correlation at the $95 \%$ confidence level, with the orange/blue colors indicating positive/negative correlation). 
When the TP surface heat source is extremely high, South China is preceded by a southerly wind at $700 \mathrm{hPa}$ and $850 \mathrm{hPa}$ (Figures 10(a) and 10(b)), and wet and warm air originates from the Bay of Bengal and the South China Sea. However, near the ground (Figure 10(c)), the southerly winds are decreased but the northerly winds are strengthened, especially on the lower reaches of the Yangtze River (such as Hunan, Guizhou, Jiangxi, and Zhejiang provinces). This vertical wind allocation is helpful for the inversion, which is very important for the sustaining of snowy/icy weather.

According to a numerical study by Wang et al. [28], plateau terrain is necessary for the formation and persistence of the quasi-stationary Kunming front. The thermodynamic effect of the terrain is a very important part of plateau and can sometimes even be regarded as a terrain equivalent. In Figures $10(\mathrm{~b})$ and 10(c), a shear line can be seen at about $105^{\circ} \mathrm{N}$, which coincides with the location of the quasistationary Kunming front, and it appears that the thermal condition of the TP can influence the quasi-stationary front. However, further evidence is needed to establish whether this idea is reliable.

\section{Summary and Discussion}

Based on the NCEP/DOE data, this paper analyzes the features of TP surface heating in January 2008 and its possible impact on atmospheric circulation and the severe ice/snow weather event that occurred in South China.

(1) It is found that the TP surface heat source shows extreme fluctuations and a pronounced heating effect in January 2008 compared to average climatic data, and the three peak heating periods coincide with the peak times of the snow disaster. The Siberian high is much more pronounced in January 2008 compared with climatic records, which is very important for the cold event in South China. The vapor supply for the freezing rain in South China can be divided into three components: (1) the westerly wind at about $25^{\circ} \mathrm{N}$; (2) the southwesterly wind from the Bay of Bengal; and (3) the southeasterly wind from the South China Sea.

(2) TP heating is conducive to the formation and sustaining of the Siberian high, which facilitates the flow of cold, dry Siberian air from the edge of the TP down to Central and South China. At $850 \mathrm{hPa}$ and the layers higher than it, TP heating strengthens the southerly wind and supplies moisture to South China. However, at near-surface levels $(925 \mathrm{hPa}), \mathrm{TP}$ heating is more likely to strengthen the northerly wind and to introduce cold, dry air to more southern regions. This up warm/down cold configuration is conducive to the creation of a thermal inversion in South China.

(3) Two Rossby wave trains can be seen at $500 \mathrm{hPa}$ and $300 \mathrm{hPa}$ at midlatitudes (approximately $20-40^{\circ} \mathrm{N}$; Figures 3(a) and 5(a)). Correlation analysis (Figures 3(b) and 5(b)) reveals that these wave trains may be influenced by abnormal TP surface heating. A comparison of the features of Rossby wave activity in December 2007 and January 2008 showed that when the TP changed swiftly from a heat sink (in December 2007) to a heat source (in January 2008), the Rossby wave propagated downstream from the TP to South
China at middle and upper layers of the atmosphere and provided energy for the snow and ice disaster that occurred in South China. Therefore, it can be inferred that the TP heating anomaly may influence the motivation and spreading of the Rossby wave train in midlatitudes.

\section{Conflict of Interests}

The authors declare that there is no conflict of interests regarding the publication of this paper.

\section{Acknowledgments}

This work was supported by the National Key Basic Research and Development Project of China (Grant no. 2012CB417202), the National Natural Science Foundation of China (Grant nos. 91337215, 41175045, and U1133603), and the Special Fund for Meteorological Research in the Public Interest (Grant no. GYHY201206042).

\section{References}

[1] M. Yanai and C. Li, "Mechanism of heating and the boundary layer over the Tibetan Plateau," Monthly Weather Review, vol. 122, no. 2, pp. 305-323, 1994.

[2] G. Li, Dynamic Meteorology of the Tibetan Plateau, China Meteorological Press, Beijing, China, 2007, (Chinese).

[3] A. Eliassen and E. Palm, "On the transfer of energy in stationary mountain waves," Geofysiske Publikasjoner Geophysica Norvegica, vol. 22, pp. 1-23, 1961.

[4] R. A. Plumb, "On the three-dimensional propagation of stationary waves," Journal of the Atmospheric Sciences, vol. 42, no. 3, pp. 217-229, 1985.

[5] E. DeWeaver and S. Nigam, "Do stationary waves drive the zonal-mean jet anomalies of the northern winter?" Journal of Climate, vol. 13, no. 13, pp. 2160-2176, 2000.

[6] B. Hoskins, "On the existence and strength of the summer subtropical anticyclones," Bulletin of the American Meteorological Society, vol. 77, no. 6, pp. 1287-1292, 1996.

[7] T. Sato and F. Kimura, "Impact of diabatic heating over the Tibetan Plateau on subsidence over Northeast Asian arid region," Geophysical Research Letters, vol. 32, no. 5, Article ID L05809, 2005.

[8] B. Wang, Q. Bao, B. Hoskins, G. Wu, and Y. Liu, "Tibetan Plateau warming and precipitation changes in East Asia," Geophysical Research Letters, vol. 35, no. 14, Article ID L14702, 2008.

[9] M. A. Haynes, K.-J. S. Kung, J. S. Brandt, Y. Yongping, and D. M. Waller, "Accelerated climate change and its potential impact on Yak herding livelihoods in the eastern Tibetan plateau," Climatic Change, vol. 123, no. 2, pp. 147-160, 2014.

[10] G. Liu, R.-G. Wu, and Y.-Z. Zhang, "Persistence of snow cover anomalies over the Tibetan Plateau and the implications for forecasting summer precipitation over the Meiyu-Baiu Region," Atmospheric and Oceanic Science Letters, vol. 7, no. 2, pp. 115-119, 2014.

[11] Y. F. Zhu, B. Zhang, and L. X. Chen, "Thermal difference between the Tibetan Plateau and the plain east of Plateau and its influence on rainfall over China in the summer," Chinese Science Bulletin, vol. 55, no. 14, pp. 1437-1444, 2010. 
[12] M. Q. Jian, H. B. Luo, and Y. T. Qian, "On the relationships between the summer rain fall and the atmospheric heat source over the eastern Tibetan Plateau and the western pacific warm pool," Journal of Tropical Meteorology, vol. 10, no. 2, pp. 133-143, 2004.

[13] H. Ueda and T. Yasunari, "Role of warming over the Tibetan Plateau in early onset of the summer monsoon over the Bay of Bengal and the South China Sea," Journal of the Meteorological Society of Japan, vol. 76, no. 1, pp. 1-12, 1998.

[14] T. Tamura, K. Taniguchi, and T. Koike, "Mechanism of upper tropospheric warming around the Tibetan Plateau at the onset phase of the Asian summer monsoon," Journal of Geophysical Research D: Atmospheres, vol. 115, no. 2, Article ID D02106, 2010.

[15] X. J. Zhou, P. Zhao, J. M. Chen, L. Chen, and W. Li, "Impacts of thermodynamic processes over the Tibetan Plateau on the Northern Hemispheric climate," Science in China Series D: Earth Sciences, vol. 52, no. 11, pp. 1679-1693, 2009.

[16] W. Zhou, J. C. L. Chan, W. Chen, J. Ling, J. G. Pinto, and Y. Shao, "Synoptic-scale controls of persistent low temperature and icy weather over Southern China in January 2008," Monthly Weather Review, vol. 137, no. 11, pp. 3978-3991, 2009.

[17] L. Gu, K. Wei, and R. H. Huang, "Severe disaster of blizzard, freezing rain and low temperature in January 2008 in China and its association with the anomalies of East Asia monsoon system," Climatic and Environmental Research, vol. 13, no. 4, pp. 405-418, 2008 (Chinese).

[18] E. Kalnay, M. Kanamitsu, R. Kistler et al., "The NCEP/NCAR 40-year reanalysis project," Bulletin of the American Meteorological Society, vol. 77, no. 3, pp. 437-471, 1996.

[19] T. Wang, G. Wu, and M. Ying, "Comparison of diabatic heating data from NCEP/NCAR(I,II) and ERA40," Acta Scientiarum Natralium Universitatis Sunyatseni, vol. 50, no. 5, pp. 128-134, 2011.

[20] M. Song, T. Wu, and Z. Qian, "Verification of NCEP surface heat flux over QXP and its application to summer precipitation forecast," Plateau Meteorology, vol. 19, no. 4, pp. 467-475, 2000 (Chinese).

[21] W. Ebisuzaki, M. Kanamitsu, J. Potter et al., "An overview of reanalysis-2," in Proceedings of the 23rd Climate Diagnostics and Prediction Workshop, pp. 26-30, 1998.

[22] M. Kanamitsu, W. Ebisuzaki, J. Woollen et al., "NCEP-DOE AMIP-II reanalysis (R-2)," Bulletin of the American Meteorological Society, vol. 83, no. 11, pp. 1631-1559, 2002.

[23] K. Takaya and H. Nakamura, "A formulation of a wave-activity flux for stationary Rossby waves on a zonally varying basic flow," Geophysical Research Letters, vol. 24, no. 23, pp. 2985-2988, 1997.

[24] K. Takaya and H. Nakamura, "A formulation of a phaseindependent wave-activity flux for stationary and migratory quasi-geostrophic eddies on a zonally varying basic flow," Journal of the Atmospheric Sciences, vol. 58, no. 6, pp. 608-627, 2001.

[25] J. Yu, Y. M. Liu, and G. X. Wu, "An analysis of the diabatic heating characteristic of atmosphere over the Tibetan Plateau in winter II: interannual variation," Acta Meteorologica Sinica, vol. 69, no. 1, pp. 89-98, 2011 (Chinese).

[26] Z. Y. Wang and Y. H. Ding, "Climate change of the cold wave frequency of China in the last 53 years and the possible reasons," Chinese Journal of Atmospheric Science, vol. 30, no. 6, pp. 10681076, 2006 (Chinese).

[27] S. Tao, J. Wei, F. Liang et al., "Analysis of high impact weather induced by the downstream effect of Rossby waves," Meteorological Monthly, vol. 36, no. 7, pp. 81-93, 2010 (Chinese).
[28] M. Wang, X. Duan, H. Li, and R. Fu, "A numerical study of the effect of terrain on Kunming Quasi-stationary front," Meteorological Monthly, vol. 39, no. 9, pp. 77-83, 2009 (Chinese). 

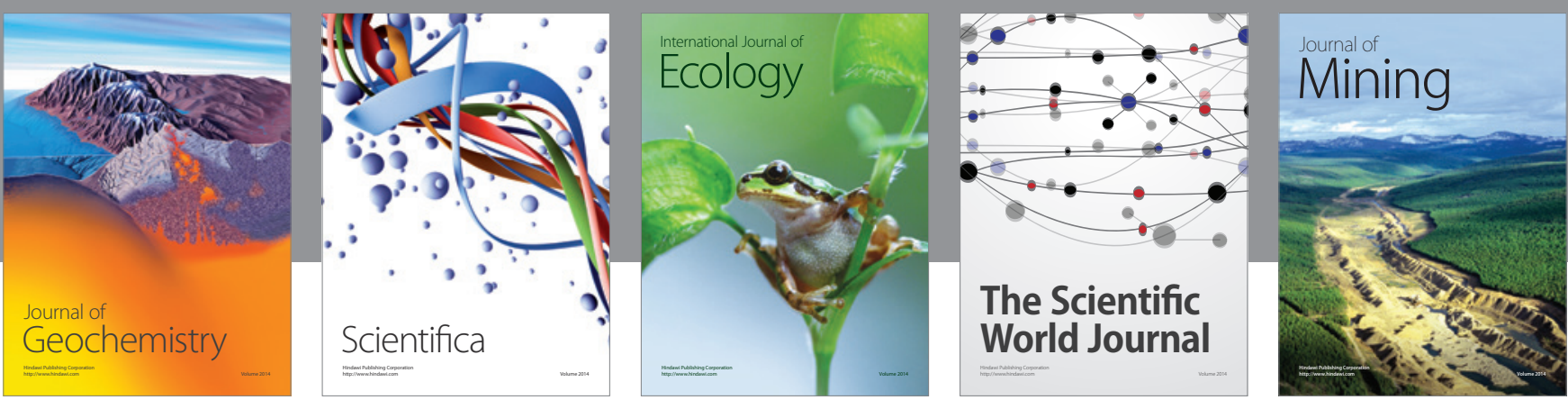

The Scientific World Journal
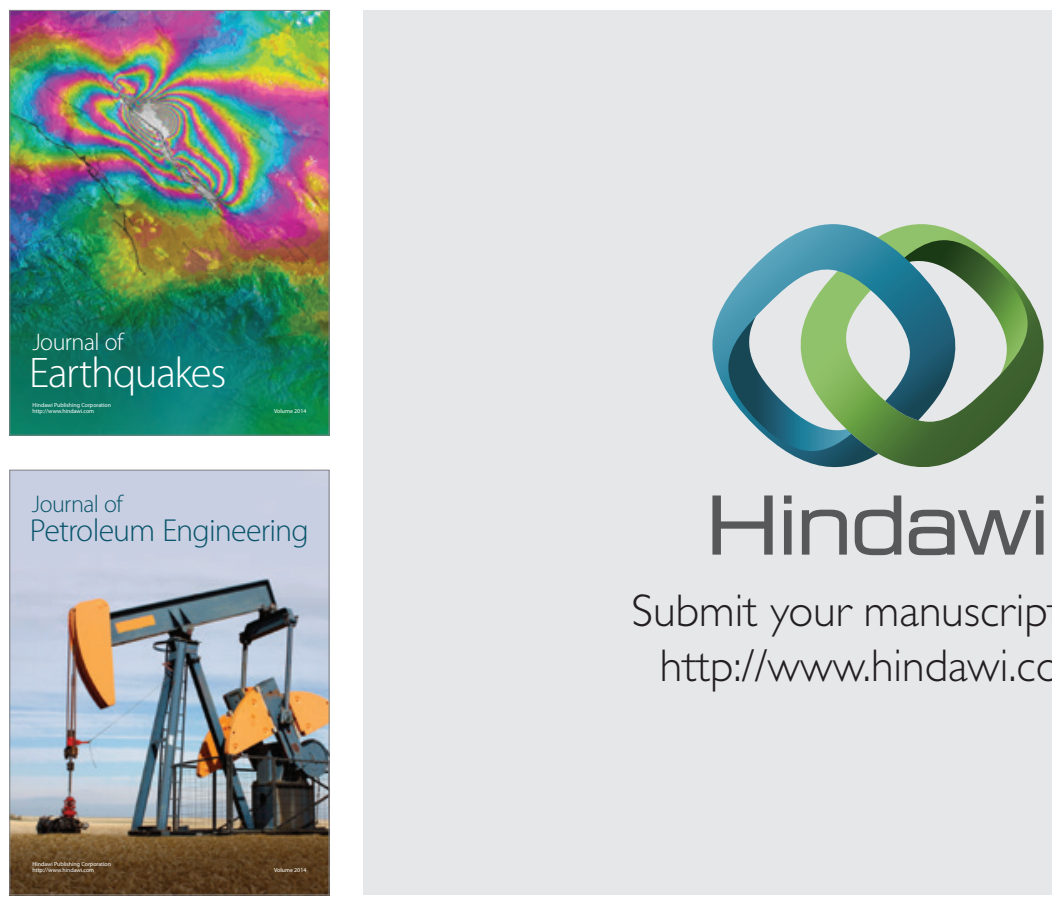

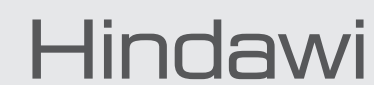

Submit your manuscripts at

http://www.hindawi.com
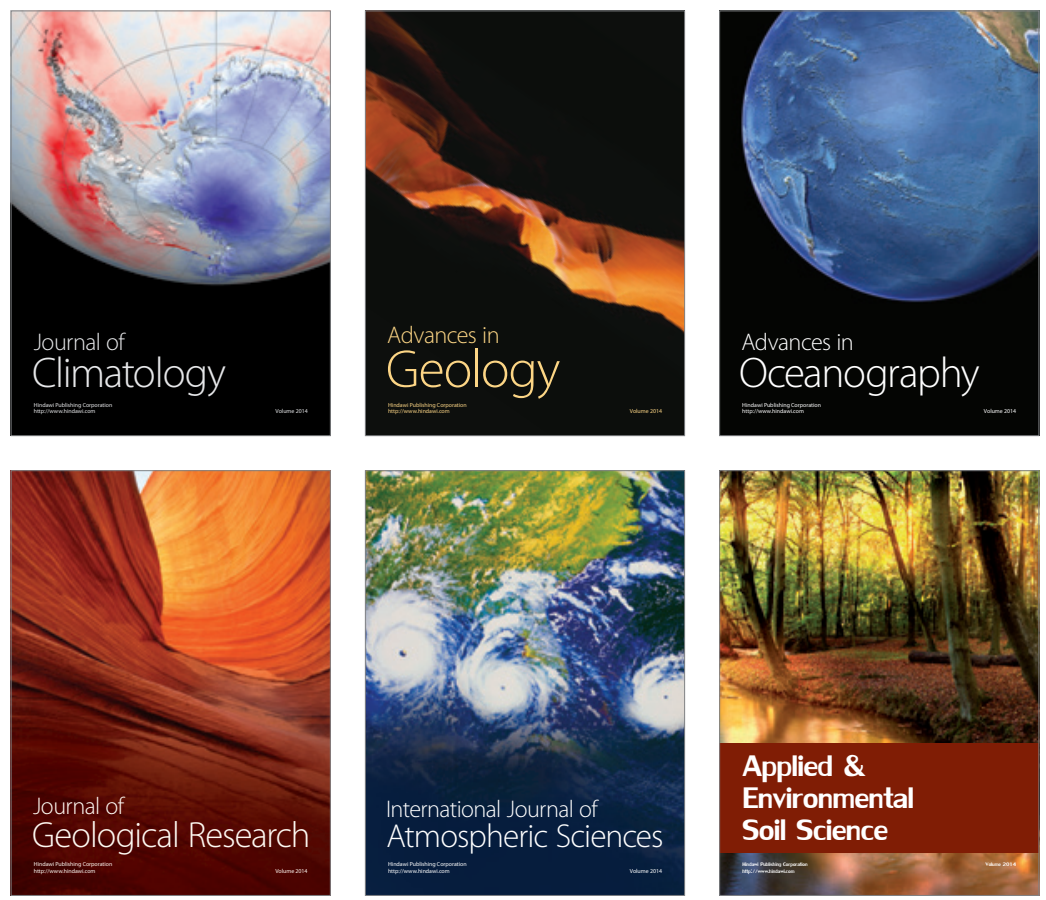
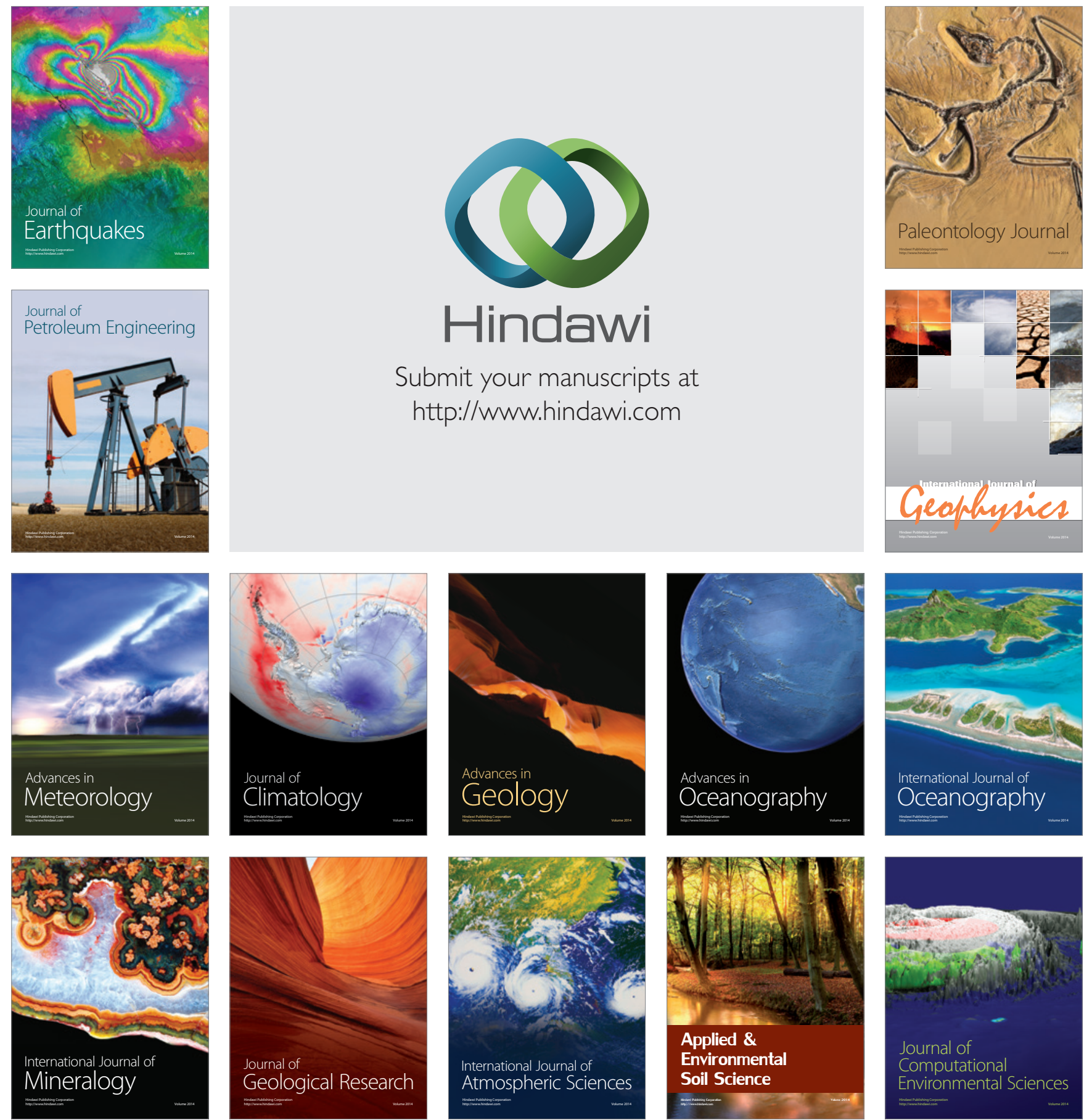